\title{
Stable nucleosome positioning and complete repression by the yeast $\alpha 2$ repressor are disrupted by amino-terminal mutations in histone $\mathrm{H4}$
}

\author{
Sharon Y. Roth, ${ }^{1,2}$ Mitsuhiro Shimizu, ${ }^{1,3}$ Lianna Johnson, ${ }^{4}$ Michael Grunstein, ${ }^{4}$ \\ and Robert T. Simpson ${ }^{1}$ \\ ${ }^{1}$ Laboratory of Cellular and Developmental Biology, National Institute of Diabetes and Digestive and Kidney Diseases, \\ National Institutes of Health, Bethesda, Maryland 20892 USA; ${ }^{4}$ Molecular Biology Institute, Department of Biology, \\ University of California, Los Angeles, California 90024 USA
}

\begin{abstract}
Nucleosomes are positioned in the presence of the yeast repressor $\alpha 2$ in minichromosomes containing the $\alpha 2$ operator and on the promoters of a-cell-specific genes regulated by $\alpha 2$. To investigate the possibility that $\alpha 2$ directs nucleosome position through an interaction with a component of the core particle, we analyzed chromatin structures adjacent to the operator in $\alpha$ cells containing mutations in the amino-terminal region of histone H4. Deletion or point mutation of specific amino acids in histone $H 4$ altered the location and/or stability of nucleosomes adjacent to the $\alpha 2$ operator. These changes in chromatin structure were accompanied by partial derepression of a $\beta$-galactosidase reporter construct under $\alpha 2$ control, even though $\alpha 2$ remained bound to its operator sequence. Our data suggest that complete repression by $\alpha 2$ requires stable positioning of nucleosomes in promoter regions and this positioning involves the conserved amino-terminal region of histone $\mathbf{H} 4$.
\end{abstract}

[Key Words: $\alpha 2$; repression; nucleosome; histone $\mathrm{H} 4$; transcription; chromatin]

Received August 14, 1991; revised version accepted January 8, 1992.

Activation or repression of cell-type-specific genes by products of the MAT locus determines mating type in the yeast Sacchromyces cerevisiae (for review, see Dranginis 1986; Nasmyth and Shore 1987; Herskowitz 1989; Dolan and Fields 1991). Two of these proteins, $\alpha 2$ and a1, share homology with homeo proteins important in the determination of cell type in other systems (Laughton and Scott 1984; Hall and Johnson 1987). $\alpha 2$ functions to repress a-cell-type-specific gene expression in haploid $\alpha$ cells and diploid $\mathbf{a} / \alpha$ cells through cooperative interactions with a non-cell-type-specific protein, MCMl (Wilson and Herskowitz 1986; Keleher et al. 1988,1989 |. In addition, $\alpha 2$ forms a heterodimer with the MATal protein in diploid cells to repress haploid-specific gene expression (Jensen et al. 1983; Miller et al. 1985; Goutte and Johnson 1988; Dranginis 1990). The mechanisms by which the $\alpha 2 / \mathrm{MCM} 1$ or a1/ $\alpha 2$ complexes repress transcription are not known.

The $\alpha 2 / M C M 1$ complex binds to a 32 -bp sequence located $\sim 200$ bp upstream of the mRNA start sites of five a-cell-type-specific genes (Wilson and Herskowitz 1986;

\footnotetext{
${ }^{2}$ Corresponding author.

${ }^{3}$ Present address: Laboratory of Analytical Chemistry, Tokyo College of Pharmacy, Hachioji, Tokyo 192-03 Japan.
}

Keleher et al. 1988, 1989; Passmore et al. 1988, 1989|. This operator sequence can confer repression in the presence of $\alpha 2$ when inserted either upstream or downstream of heterologous promoter-activating elements (Johnson and Herskowitz 1985). The ability of the operator to act at a distance and in different contexts suggests that changes in chromatin structure could be involved in the repression of a-cell-type-specific gene expression by $\alpha 2$ / MCM1.

We reported previously a precise and stable positioning of nucleosomes in minichromosomes containing the $\alpha 2$ operator in haploid $\alpha$ and diploid a/ $\alpha$ cells (Roth et al. 1990; Simpson 1990). A precise localization of nucleosomes in the minichromosomes was not observed in the absence of $\alpha 2$, in haploid a cells (Roth et al. 1990). Positioned nucleosomes adjacent to the $\alpha 2$ operator in $\alpha$ cells, but not in a cells, have also been observed upstream of STE6 and BAR1, two chromosomal genes regulated by $\alpha 2$ (Shimizu et al. 1991). The occurrence of nucleosomes over different sequences in very similar positions relative to the operator in the minichromosomes and upstream of these genes suggests that their positions might be directly determined by $\alpha 2$, or the $\alpha 2 / \mathrm{MCM} 1$ complex. The ability of the operator to serve as a dominant nucleosome-positioning signal relative to an endog- 
Figure 1. Structure of TALS minichromosome, STE6, and H4 mutants. (A) The chromatin structure of the TRP1/ARS 1 derivative plasmid TALS (Roth et al. 1990) in $\alpha$ and $a / \alpha$ cells is depicted. The positions of nucleosomes I-X and major MNase cut sites present in chromatin are indicated (in map units; arrowheads). The ARS1 elements are located in a hypersensitive region between nucleosomes $\mathrm{X}$ and I. The $\alpha 2$ operator is located between nucleosomes IV and V. The TRP1 transcription unit is depicted by the curved arrow. In a cells, nucleosomes are not stably positioned in TALS chromatin. $(B)$ The chromatin structure of the $5^{\prime}$ end of the STE6 gene in $\alpha$ cells is depicted (Shimizu et al. 1991; also see Fig. 5). Major MNase cut sites in chromatin are shown (arrowheads), and inferred positions of nucleosomes are depicted. The locations of the $\alpha 2$ operator, a putative TATA element, and the transcription start site (bent arrow) are also indicated (Wilson and Herskowitz 1986). (C) The first 30 amino acids of histone $\mathrm{H} 4$ are shown, and sites of post-translational acetylation $(+)$ or phosphorylation $(-$ ) are indicated (van Holde 1989). Deletion mutants used in this study are depicted below the sequence (Kayne et al. 1988). Point mutations $\left({ }^{*}\right)$ were also used in which amino acids 16,17 , or 18 were changed to glycyl residues (Johnson et al. 1990).
A

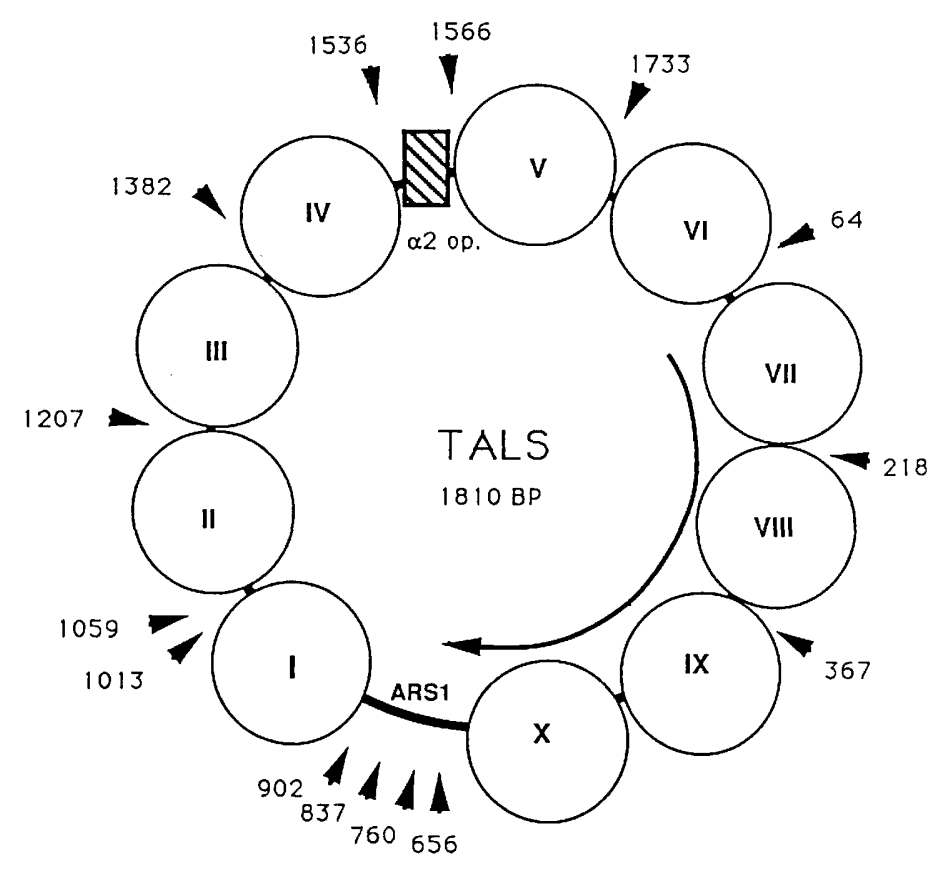

B

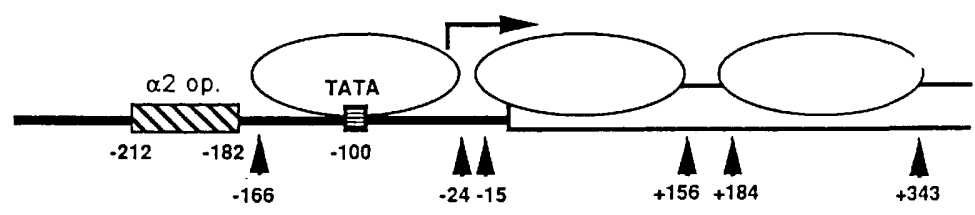

C

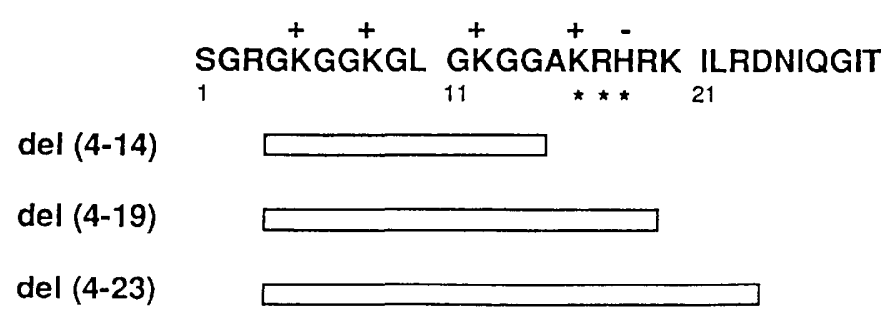

enous-positioning signal in a minichromosome in $\alpha$ cells supports this hypothesis further (Simpson 1990). Positioning of a nucleosome in promoter regions might inhibit transcription through occlusion of cis-acting elements (for review, see Grunstein 1990a,b; Wolffe 1990; Simpson 1991). Location of a cis-acting element involved in replication near the center of a nucleosome has been demonstrated to inhibit its function in vivo (Simpson 1990).

If nucleosomes are positioned adjacent to the $\alpha 2$ operator through an interaction between the $\alpha 2 / \mathrm{MCM} 1 \mathrm{com}$ plex and a component of the core particle, then mutations, in particular histone molecules, might disrupt this interaction. To test this idea, we examined the structure of a minichromosome and STE6 in $\alpha$ cells engineered to express amino-terminal mutations in histone H4. Deletions in $\mathrm{H} 4$ that extend into the globular core region necessary for nucleosome assembly are lethal (Kayne et al. 1988). Removal of amino acids 4-19, 4-23, or 4-28 in histone $\mathrm{H} 4$ does not lead to cell death but results in a considerable extension of the cell cycle and sterility, as a result of aberrant expression of the silent mating loci (Kayne et al. 1988). Derepression of these loci in the presence of these H4 mutations is specific; other genes such as PHO5 and CUP1 are not activated. Point mutation (individually) of a repressor domain (Durrin et al. 1991), including amino acids $16-19$, has effects similar to the above deletions in H4 (Johnson et al. 1990; Megee et al. 1990; Park and Szostak 1990) and can be suppressed by mutations in a known regulator of the silent mating loci, SIR3 (Johnson et al. 1990). In addition, H4 amino-terminal sequences are required for efficient activation of a number of inducible promoters (Durrin et al. 1991) and are involved in position effects regulating gene expression near telomeres (Aparico et al. 1991).

Here, we report that mutations in the $\mathrm{H} 4$ amino-ter- 


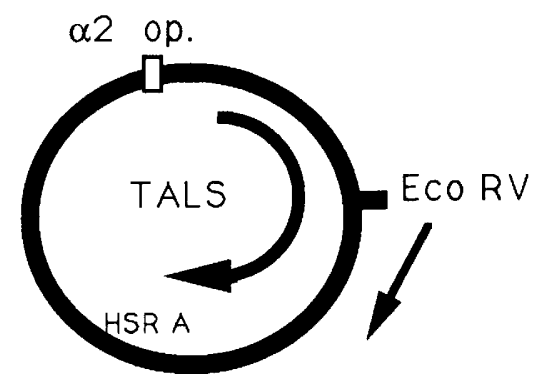

A
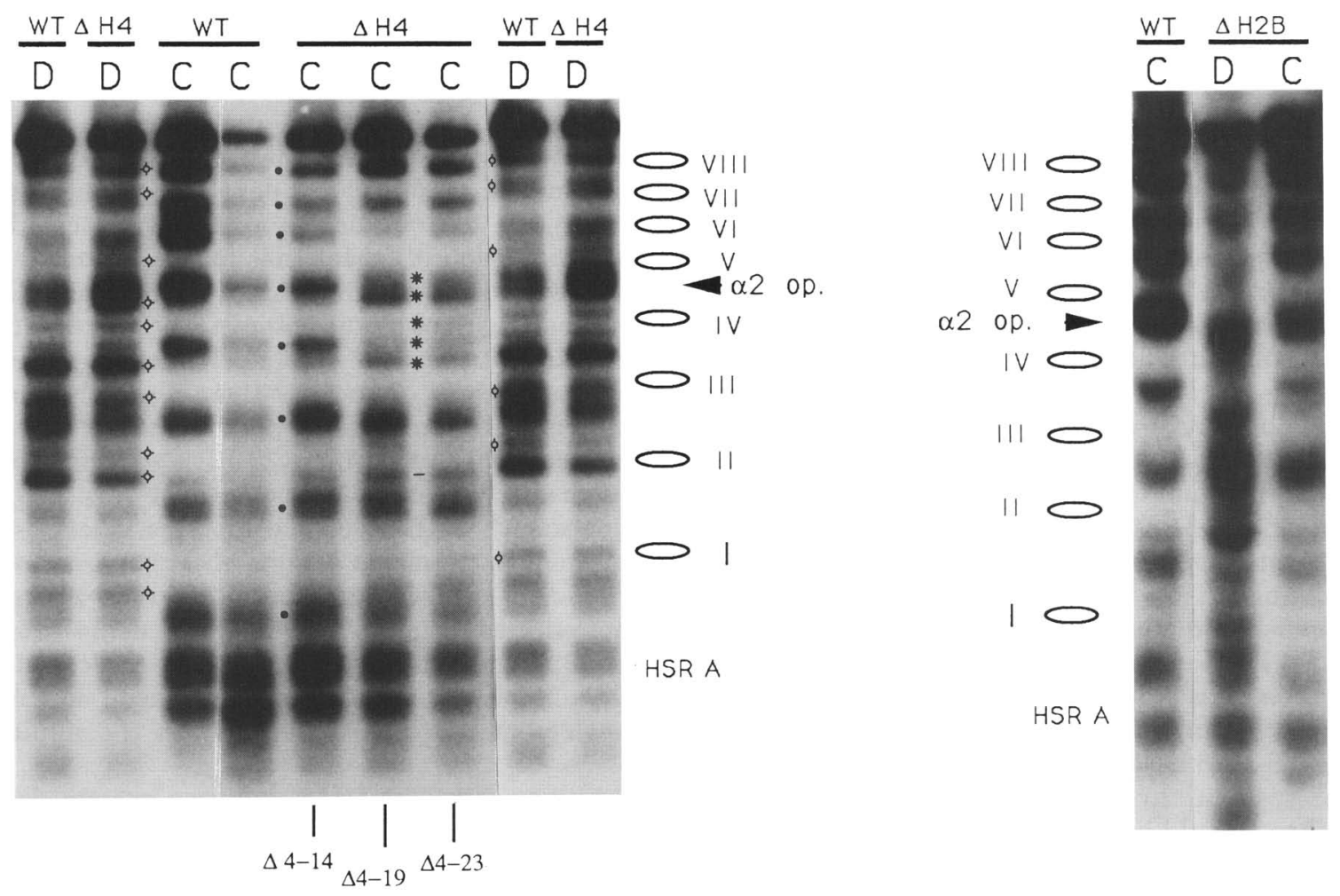

Figure 2. Effects of deletion of histone $\mathrm{H} 4$ or $\mathrm{H} 2 \mathrm{~B}$ amino-terminal regions on TALS chromatin structure. (A) MNase cut sites in TALS chromatin (C) or DNA (D) were mapped in a clockwise direction from an EcoRV restriction site at 385 map units (Fig. 1A) in $\alpha$ cells containing wild-type (WT) $\mathrm{H} 4$ or an $\mathrm{H} 4$ deletion mutant as indicated. Chromatin isolated from an unrelated $\alpha$ cell (S.C3) used in previous studies (Roth et al. 1990) was also analyzed for comparative purposes and is shown in the right-most WT lane. The inferred positions of nucleosomes I-VIII are shown at the side, as is the location of the $\alpha 2$ operator (large arrowhead) and the nucleasehypersensitive region HSR A. The naked DNA lanes (D) are presented twice to aid comparison between samples. Black dots indicate cut sites in chromatin that demarcate boundaries between nucleosomes in $\alpha$ cells with wild-type H4. Symbols next to the second lane indicate sites exposed in naked DNA that are protected in wild-type $\alpha$-cell chromatin. Note the increased cutting (indicated by asterisks) in the regions normally protected by nucleosomes IV and V in the presence of del (4-19) and del (4-23). The dash indicates a cut site in the region of nucleosome II, which may also be somewhat more exposed in the presence of these deletions. Symbols between lanes 7 and 8 indicate sites in naked DNA that are still protected in the presence of del $(4-19)$ and del (4-23) in the regions of nucleosomes I, II, III, V, VII, and VIII. (B) MNase cut sites in chromatin (C) and DNA (D) in cells containing wild-type (WT) H2B or an $\mathrm{H} 2 \mathrm{~B}$ amino-terminal deletion mutant $(\Delta \mathrm{H} 2 \mathrm{~B})$ were mapped as above.

minal region destabilize nucleosome position adjacent to the $\alpha 2$ operator in a minichromosome and upstream of STE6. The functional consequences of these alterations of chromatin structure were evaluated using a $\beta$-galactosidase reporter gene inserted into the a-cell-specific gene $M F \mathbf{a} 2$. Although $\beta$-galactosidase expression is not detected in $\alpha$ cells containing wild-type $\mathrm{H} 4$, it is clearly evident in $\alpha$ cells containing $\mathrm{H} 4$ amino-terminal mutations, even though in vivo dimethylsulfate (DMS) footprints indicate that $\alpha 2$ is bound to its operator in these 
cells. Our data support a direct role for nucleosome position in the regulation of a-cell-specific gene expression.

\section{Results}

Amino-terminal mutations in $\mathrm{H} 4$ alter the structure of the TALS minichromosome

In haploid $\alpha$ cells and diploid a/ $\alpha$ cells, the TALS minichromosome is packaged into an array of stably positioned nucleosomes, excluding only those sequences $3^{\prime}$ to the TRP1 gene, which include the ARS1 elements (Fig. 1A) (Roth et al. 1990). Two nucleosomes, IV and V, directly flank the $\alpha 2$ operator. High-resolution primer-extension mapping of this region indicates that these nucleosomes are positioned very precisely (Shimizu et al. 1991; Fig. 3, below) and are located within a few base pairs of the edge of the operator sequence as defined in vitro (Keleher et al. 1988). In a cells, in the absence of $\alpha 2$, these nucleosomes are not positioned stably, and nucleosomes on the plasmid are located nearly randomly.

To assess the effects of amino-terminal deletions in histone $\mathrm{H} 4$ on the structure of TALS, the plasmid was introduced into $\alpha$ cells bearing either a single-copy, plasmid-borne, wild-type $\mathrm{H} 4$ gene (PKY999) or an H4 gene with deletion of amino acids 4-14 [del (4-14); PKY917], 4-19 [del (4-19); PKY918], or 4-23 [del (4-23); PKY913] (Fig. 1C). Both chromosomal copies of $\mathrm{H} 4$ (H4-1, H4-2) are disrupted in these strains, and the plasmid-borne gene is the sole source of $\mathrm{H} 4$ (Kayne et al. 1988). Because strains bearing del (4-19) and del (4-23) express both aand $\alpha$-mating-type genes owing to derepression of the silent mating loci (Kayne et al. 1988), they are phenotypically diploid for mating-type functions. However, $\alpha 2$ represses a-cell-type-specific gene expression (Herskowitz 1989) and induces ordered nucleosome positions on the TALS minichromosome (Roth et al. 1990) in diploid a/ $\alpha$ cells as well as in haploid $\alpha$ cells. Any changes observed in TALS structure in the presence of del $(4-19)$ or del $(4-23)$, then, should be related to changes in the structure of $\mathrm{H} 4$ rather than in the expression of $\alpha 2$ or other mating-type genes.

The structure of the TALS plasmid was first examined in the various strains by micrococcal nuclease (MNase) digestion and indirect end-labeling (Fig 2A). Nucleosome position is inferred in these studies by the separation of MNase cut sites in chromatin by $\sim 140$ bp with protection of intervening sites present in naked DNA. Comparison of structures inferred from such data to those observed in electron micrographs of TRP1/ARS1 chromatin indicate a close correspondence between the inferred and the actual structure of TRP1/ARS1 (Pederson et al. 1986).

Indirect end-labeling of TALS chromatin isolated from the strains expressing a single copy of wild-type $\mathrm{H} 4$ or del $(4-14)$ indicates that nucleosomes are positioned on the plasmid into an array identical to that observed previously in other $\alpha$ cells. A series of discrete MNase cut sites separated by 140 bp (dots in Fig. 2A), identical to those characterized previously in $\alpha$ cells (Roth et al. 1990), is observed in these strains (cf. lanes 3, 4, and 5,
Fig. 2A). Also, intervening sites exposed in naked DNA are protected from digestion in these chromatin samples (see symbols adjacent to lane 2, Fig. 2A). These data indicate that neither reduction in $\mathrm{H} 4$ copy number nor deletion of amino acids 4-14 alters the position or stability of nucleosomes on the TALS minichromosome.

In striking contrast, exposure of particular MNase cut sites is altered in the presence of del (4-19) and del (4 23). Nuclease-sensitive sites in chromatin that normally demarcate the borders between nucleosomes III and IV (fifth dot from top), IV and V (fourth dot from top), and V and VI (third dot from top) are diminished in these strains. Also, cut sites in these regions normally protected from digestion in chromatin relative to naked DNA are exposed (asterisks, Fig. 2A). These differences are most pronounced in the region adjacent to the operator normally protected by nucleosome IV. One cut site in the region protected by nucleosome II may also be somewhat more exposed relative to flanking sites in the presence of del (4-19) and del (4-23) (dash, adjacent to lane 6; Fig. 2A), but the surrounding hypersensitive sites and protection of other bands in this region are consistent with continued presence of nucleosome II in these strains. Positions of nucleosomes elsewhere on the plasmid are not affected by these deletions, as evidenced by the persistence of hypersensitive sites in chromatin and protection of intervening sites in naked DNA (see symbols adjacent to lane 7, Fig. 2A). The positions of nucleosomes I, VII, and VIII, for example (Fig. 2A), appear unchanged in the presence of these deletions. Other mapping experiments confirm that the positions of nucleosomes elsewhere on the plasmid (VI-X, Fig. 1) are not affected (data not shown). Thus, del (4-19) and del (4-23) largely affect the locations of nucleosomes near the $\alpha 2$ operator without causing general alterations in nucleosome positions elsewhere on the minichromosome.

The structure of TALS was also examined in an $\alpha$ strain bearing a 30 -amino-acid deletion in the aminoterminal region of histone $\mathrm{H} 2 \mathrm{~B}$ [amino acids 3-32 (TSY155); Wallis et al. 1983]. No changes were observed in the positions of any nucleosomes on the plasmid (Fig. $2 B)$, although cleavage at the edges of nucleosomes in the presence of the $\mathrm{H} 2 \mathrm{~B}$ deletion may be slightly more pronounced than in the presence of wild-type H2B (evidenced by a broadening of some bands in Fig. 2B). Thus, the changes we observe in the presence of the histone $\mathrm{H} 4$ mutations are not observed upon similar mutation of another histone.

\section{High-resolution mapping of nucleosome positions in the TALS minichromosome}

Changes in the positions of nucleosomes I-V in the presence of the $\mathrm{H} 4$ mutation del (4-23) were examined more closely by primer extension mapping (Fig. 3), which allows precise definition of the locations of nuclease-hypersensitive sites and protected regions in chromatin by comparison to cut sites in naked DNA and to sequencing ladders on the same gel. 
A

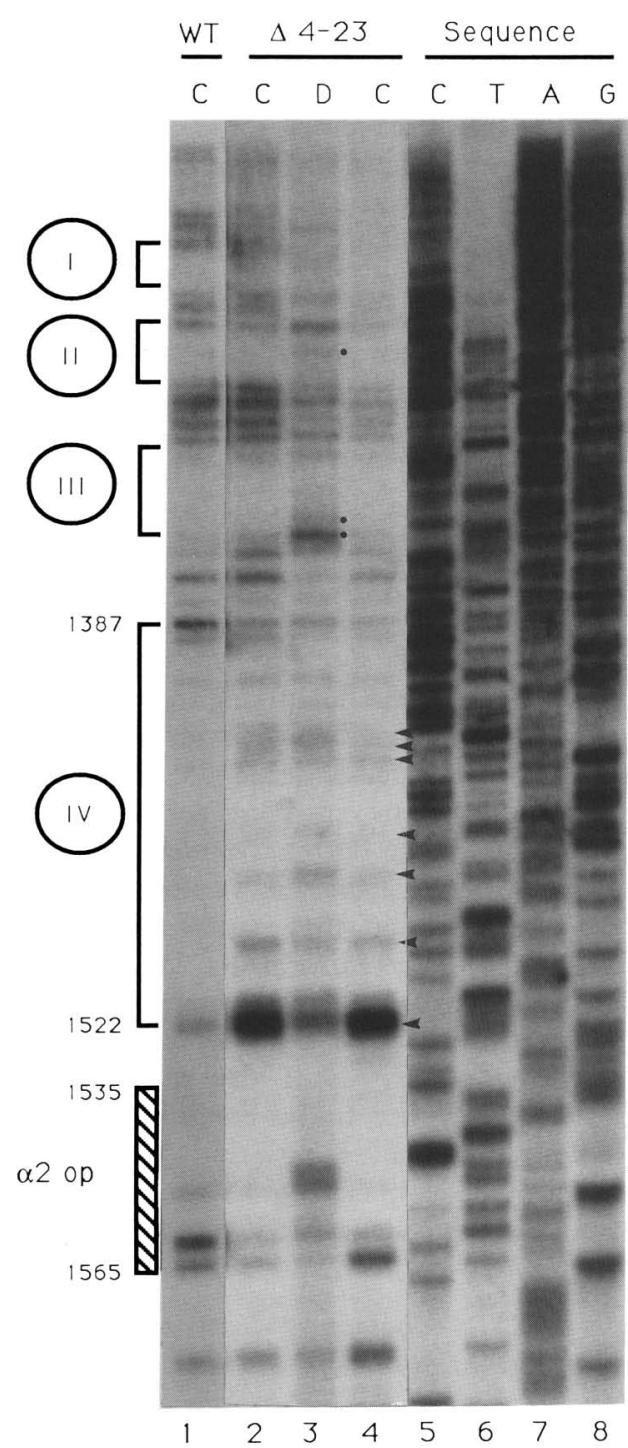

Figure 3. High-resolution mapping of TALS nucleosomes IV and $\mathrm{V}$ in the presence of wild-type $\mathrm{H} 4$ and del (4-23) $(A)$ MNase cut sites in chromatin $(\mathrm{C})$ and DNA (D) were analyzed by primer extension. All samples shown were analyzed in the same gel. The positions of nucleosomes I-IV and the $\alpha 2$ operator are indicated. Cut sites exposed in chromatin in the presence of the deletion (lanes 2,4), but not in wild-type cells (lane 1), are indicated by arrowheads. Sites protected relative to naked DNA (lane 3 ) are indicated by dots. The locations of cut sites were determined by comparison to dideoxy sequencing reactions, as shown (lanes 5-8). Chromatin or DNA was digested with $0.5 \mathrm{U} / \mathrm{ml}$ of MNase (all but WT) or $1 \mathrm{U} / \mathrm{ml}(\mathrm{WT})$. (B) DNase I cut sites in chromatin (C) and DNA (D) were also analyzed by primer extension. The position of nucleosome $\mathrm{V}$ (in map units), as determined by MNase digestion (Fig. 2A; Shimizu et al. 1991), is indicated. Locations of cut sites were determined by comparison to dideoxy sequencing reactions (not shown) as in $A$. Arrowheads indicate some of the cleavage sites in chromatin from cells containing del (4-23), which are protected in chromatin from cells containing wild-type $\mathrm{H} 4$. (O) Cut sites diminished in del (4-23) chromatin relative to wild-type

chromatin. Dashes indicate cut sites that are similarly recognized in both wild-type and del (4-23) chromatin. (Below) To facilitate comparison, lanes 3, 4, and 8 were scanned with a Molecular Dynamics computing densitometer, and profiles obtained are presented, using the same symbols as on the gel. Chromatin was digested with 0.13 (lanes 3,6), 0.25 (lanes 2,7), or $0.50 \mathrm{U} / \mathrm{ml}$ of DNase I (lanes 1,8 ), and DNA was digested with 0.01 (lane 4) or 0.025 (lane 5) U/ml. All samples were analyzed in the same gel.
B
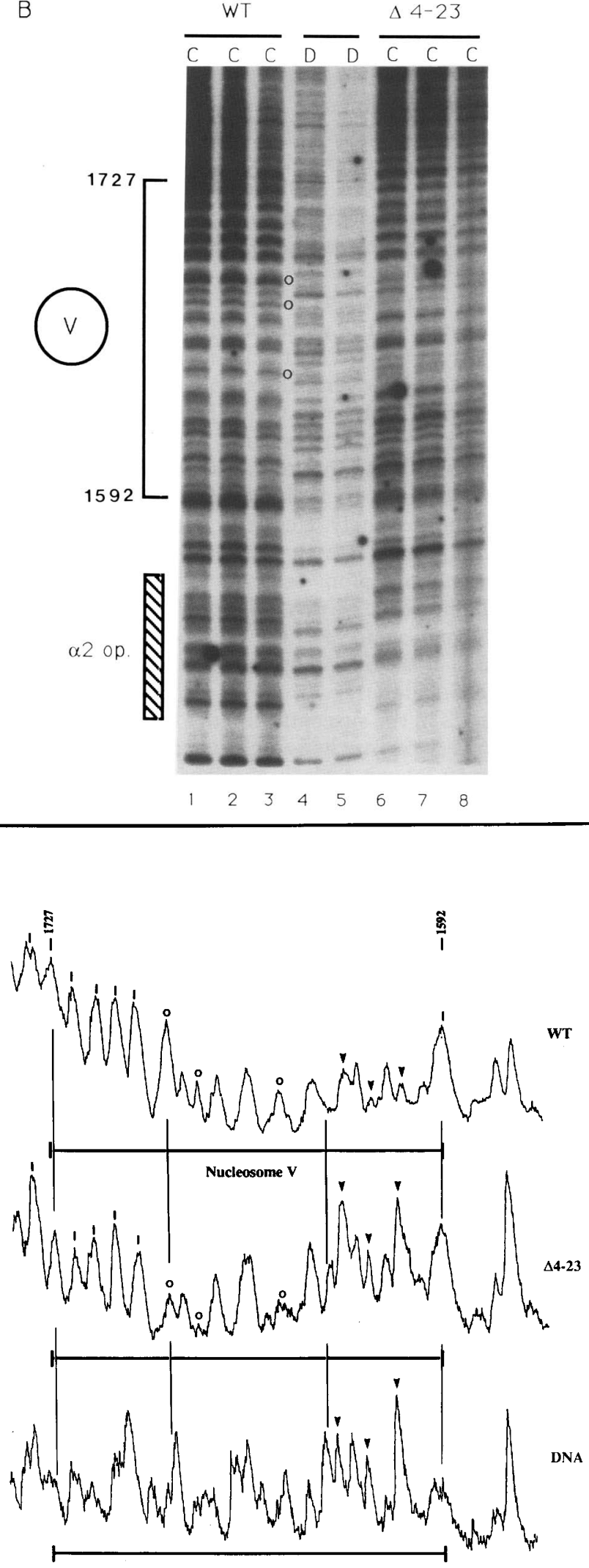

GENES \& DEVELOPMENT 
In other studies, nucleosomes flanking the $\alpha 2$ operator in the TALS minichromosome, IV and V, have been shown to be both translationally and rotationally positioned in $\alpha$ cells (Shimizu et al. 1991; WT, Fig. 3). In particular, cutting by MNase is essentially blocked between 1387 and 1522 map units by the presence of nucleosome IV and between 1592 and 1737 map units by nucleosome V. Reappearance of cutting in these regions signals loss of stable translational positioning of these nucleosomes.

Primer extension analysis revealed alterations in sensitivity to MNase in the presence of del (4-23) in the region normally protected by nucleosome IV, as shown in Fig. 3A (lanes 2,4). Several sites protected in the presence of wild-type $\mathrm{H} 4$ (cf. lanes 1 and 3 ) are exposed in the presence of this deletion (arrowheads, Fig. 3A) producing a pattern very similar to that of naked DNA, consistent with results obtained in indirect end-labeling experiments above. Interestingly, a cut site near the $\alpha 2$ operator at 1522 map units, which includes sequences from the STE6 promoter region, becomes hypersensitive to MNase in the presence of this deletion. These same sequences are hypersensitive in the presence of del (4-19) [and del (4-23)] at the STE6 chromosomal locus (see site at -166 , Fig. 5, below).

Some changes in the susceptibility of a few sites in the linker region between nucleosomes III and IV are evident in this analysis. By comparison with the above changes in the region protected by nucleosome IV, however, only minimal differences are observed in the regions of nucleosomes I, II, and III when examined at this level. Nuclease-sensitive sites are located in the same places in chromatin from the wild-type and del (4-23) strains in these regions, and sites exposed in naked DNA are protected (see dots in Fig. 3A) in chromatin from both cell types.

High-resolution mapping of the position of nucleosome $\mathrm{V}$ using MNase also revealed specific differences in the exposure of sequences adjacent to the $\alpha 2$ operator in the presence of del (4-23) (data not shown), indicating a loss of translational positioning of this nucleosome as well. Primer extension mapping of MNase cut sites provides additional evidence that del (4-23) affects the stability of nucleosome position near the $\alpha 2$ operator, in the regions of nucleosomes IV and V.

\section{Rotational positioning of nucleosomes in the presence of $\mathrm{H} 4$ amino-terminal deletions}

Rotational positioning refers to the orientation of DNA on the surface of a histone octamer, whereas translational positioning refers to the location of the nucleosome with respect to given sequences as defined above. DNase I is useful in evaluating the rotational positions of nucleosomes because it cleaves DNA within the core particle. If a nucleosome maintains a stable rotational position, a 10-bp periodicity of DNase I cuts will be observed that reflects the pitch of the double helix on the surface of the histone octamer.

Primer extension analysis of DNase I digests was per- formed to determine the rotational positioning of nucleosomes IV and V in the presence of del (4-23). A periodic pattern of cutting is observed for the nucleosome $\mathrm{V}$ region in $\alpha$ cells expressing wild-type $\mathrm{H} 4$ (Fig. 3B), indicating that this nucleosome is rotationally positioned in these cells, in agreement with previous results (Shimizu et al. 1991). Disruptions of this pattern are observed in the presence of del (4-23) (Fig. 3B). A densitometric scan of the gel in Figure 3B is presented to aid comparison between samples. Cutting near the operator (to the right, as shown in the scan) in the presence of del (4-23) resembles more closely that in naked DNA than in wildtype chromatin. Cut sites normally protected in chromatin are exposed in the presence of this deletion (arrowheads, Fig. 3B). Other sites that should be cut to preserve the $\sim 10$-bp periodicity observed in wild-type chromatin are not susceptible to nuclease (open circles, Fig. 3B). This disruption of periodic cutting indicates that nucleosome $\mathrm{V}$ is not rotationally positioned adjacent to the $\alpha 2$ operator in the presence of del (4-23). Some sites in the distal region of nucleosome $\mathrm{V}$ are cut similarly in wildtype chromatin and in chromatin containing del (4-23) (dashes, Fig. 3B), indicating that a complete disruption of chromatin structure in this region has not occurred. DNase I digests of the nucleosome IV region also indicate that this nucleosome is no longer rotationally positioned in the presence of del (4-23) (data not shown). Primer extension analysis of MNase and DNase I cut sites indicates that the amino-terminal region of $\mathrm{H} 4$ is necessary for both stable translational and rotational positioning of nucleosomes IV and V normally observed in wild-type $\alpha$ cells adjacent to the $\alpha 2$ operator.

\section{Changes in TALS topoisomer distribution in the presence of del (4-19) and del (4-23)}

In previous studies we observed that the TALS plasmid isolated from $\alpha$ cells contained an extra negative supercoil relative to the plasmid isolated from a cells (Roth et al. 1990). Because each nucleosome imparts one negative supercoil to chromatin, these data are consistent with the presence of an additional nucleosome on the plasmid in $\alpha$ cells (see Discussion, below). When we examined the distribution of TALS topoisomers isolated from $\alpha$ strains containing either the wild-type $\mathrm{H} 4$ gene or del (4-14), we observed a supercoil density similar to that observed in other $\alpha$ cells (Fig. 4). A slight shift in supercoil density (less than one supercoil) may occur in the presence of del (4-14), but in general, the topoisomer distribution in the del (4-14) strain is equivalent to that of wild-type $\alpha$ cells. In $\alpha$ cells expressing either del (4-19) or del (4-23), the distribution of supercoil density is obviously shifted, to an extent normally observed in a cells, corresponding to the loss of one negative supercoil. This shift is not observed for plasmids lacking the $\alpha 2$ operator, including another TRP1/ARS1 derivative [TAL (Roth et al. 1990); data not shown] and the $2 \mu$ circle (Kayne et al. 1988), indicating that it is a specific effect for plasmids that bind $\alpha 2$. These changes in TALS topoisomer distribution are consistent with the presence of 


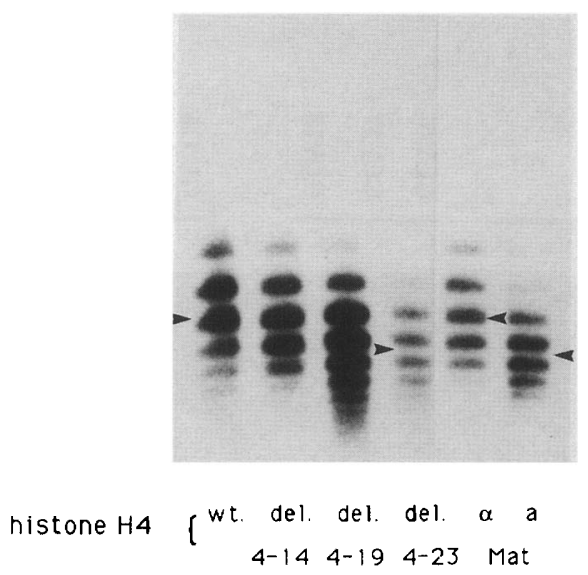

Figure 4. Distribution of TALS topoisomers in the presence of H4 amino-terminal deletions. Supercoiled DNA isolated from strains containing wild-type $\mathrm{H} 4$ (wt) or an $\mathrm{H} 4$ deletion mutant (del 4-14, del 4-19, or del 4-23 as indicated) was analyzed on agarose gels containing $40 \mu \mathrm{g} / \mathrm{ml}$ of chloroquine diphosphate, transferred to nitrocellulose, and hybridized to a probe specific for the TALS plasmid. Under these conditions, more negatively supercoiled molecules migrate slower than less negatively supercoiled molecules. The center of distribution of TALS topoisomers in each lane is indicated (arrowheads). For comparison, the distribution of topisomers in unrelated $\alpha$ (SC3) and a (E290) cells used in previous studies is also shown. All samples were analyzed on the same gel.

one less nucleosome on the plasmid in the presence of del (4-19) and del (4-23), reflecting the changes in stable nucleosome location indicated in the above mapping studies.

\section{Structure of chromosomal a-cell-specific genes in the presence of amino-terminal deletions in $\mathrm{H} 4$}

Changes in nucleosome position proximal to the $\alpha 2$ operator, like those observed in the minichromosome in the presence of del (4-19) and del (4-23), might also be expected in chromosomal copies of a-cell-specific genes regulated by $\alpha 2$. At least two of these genes, STE 6 and $B A R 1$, are packaged into a positioned nucleosomal array in $\alpha$ cells but not in a cells, analogous to the packaging of the TALS plasmid in the two cell types (Shimizu et al. 1991; Fig. 1B).

Primer extension analysis of MNase cut sites in chromatin and naked DNA indicates that this organized structure is also observed for STE6 in $\alpha$ cells containing a single copy of a wild-type $\mathrm{H} 4$ gene on a plasmid (Fig. 5, lanes $6,7,11 \mid$. Nuclease-hypersensitive sites are observed at $-166,-24$, and +184 in chromatin isolated from these cells while many intervening sites present in naked DNA (lanes 5,16$)$ are protected. In a cells, these hypersensitive sites are diminished (cf. lane 12 with lanes 6,7 , and 11). In addition, a subset of sites exposed in naked DNA are exposed in a-cell chromatin, and new hypersensitive sites are observed (cf. lane 12 with lanes 16 and 11). These data are consistent with a disruption of the chromatin structure observed in $\alpha$ cells. One hyper- sensitive site in a-cell chromatin corresponds to the location of the TATA sequence in the STE6 promoter (arrowhead, Fig. 5), consistent with an increased accessibility of this sequence in a cells. Surprisingly, the $\alpha 2$ operator sequence appears less sensitive to MNase digestion in a cells (lane 12) than in $\alpha$ cells (lane 11). We are investigating in detail in vivo protein-DNA interactions at the operator in separate studies.

We investigated the effects of del (4-19) on the chromatin structure of STE6 both in an $\alpha$ strain isogenic to the wild-type strain above (Fig. 5, lane 8) and in strains bearing an integrated copy of this $\mathrm{H} 4$ deletion in which both the $H M L$ and $H M R$ loci are converted to the same mating type as present at the MAT locus (Fig. 5, lanes $9,10)$. In effect, these strains possess either three functional copies of MAT $\alpha\left(\alpha \alpha \alpha_{;}\right.$JTY222H; lane 10) or MATa (aaa; LJY438I; lane 9). Because only a single mating type is expressed in these cells, possible complications owing to secondary effects of derepression of $H M L$ and $H M R$ are avoided.

In $\alpha$ strains carrying del $(4-19)$, a STE6 chromatin structure intermediate to that in wild-type $\alpha$ or a cells is observed (Fig. 5, lanes 8,10). Nuclease-hypersensitive sites at the ends of the regions protected by nucleosomes in normal $\alpha$ cells (e.g., at -166 and -24 ) are maintained in the presence of the deletion and, in some cases (at -166), appear to be even more sensitive to digestion. The maintenance of these sites indicates that the structure of this region is not disrupted completely by this amino-terminal deletion in $\mathrm{H} 4$. However, accessibility of numerous cut sites protected in the presence of wildtype $\mathrm{H} 4$ is clearly increased in the presence of del (4-19) (cf. bracketed region in Fig. 5, lanes 7,8,10,11), including the hypersensitive site that maps to the TATA sequence (arrowhead, Fig. 5) (Wilson and Herskowitz 1986) and two sites that map to sequences near pheromone response elements (dots, Fig. 5; Kronstad et al. 1987). The pattern of exposure of these sites in the STE6 promoter region (bracket, lanes 8,10 ) in this strain strongly resembles that observed in chromatin isolated from a cells (lane 12). We interpret this increased accessibility as an indication of decreased nucleosome stability, which allows re-exposure of these sites. Cleavage sites farther downstream, in the STE6-coding region, which are normally protected by nucleosomes in $\alpha$ cells, are also exposed in the presence of del (4-19).

In the aaa del (4-19) strain, the pattern of MNase cutting in the STE6 promoter region is similar to that observed in other a strains, as expected (cf. lanes 9 and 12). Many cut sites protected in $\alpha$-cell chromatin are no longer protected in this strain, and hypersensitive sites are observed within exposed regions that are similar to those in wild-type a cells.

Alterations in STE6 chromatin structure observed in $\alpha$ cells in the presence of del (4-19) were also observed in the presence of del (4-23). Surprisingly, del (4-14) also affected STE6 chromatin structure, although to a lesser extent than the longer deletions (data not shown). Analogous experiments indicate that the structure of the $B A R 1$ promoter region is altered in a very similar man- 


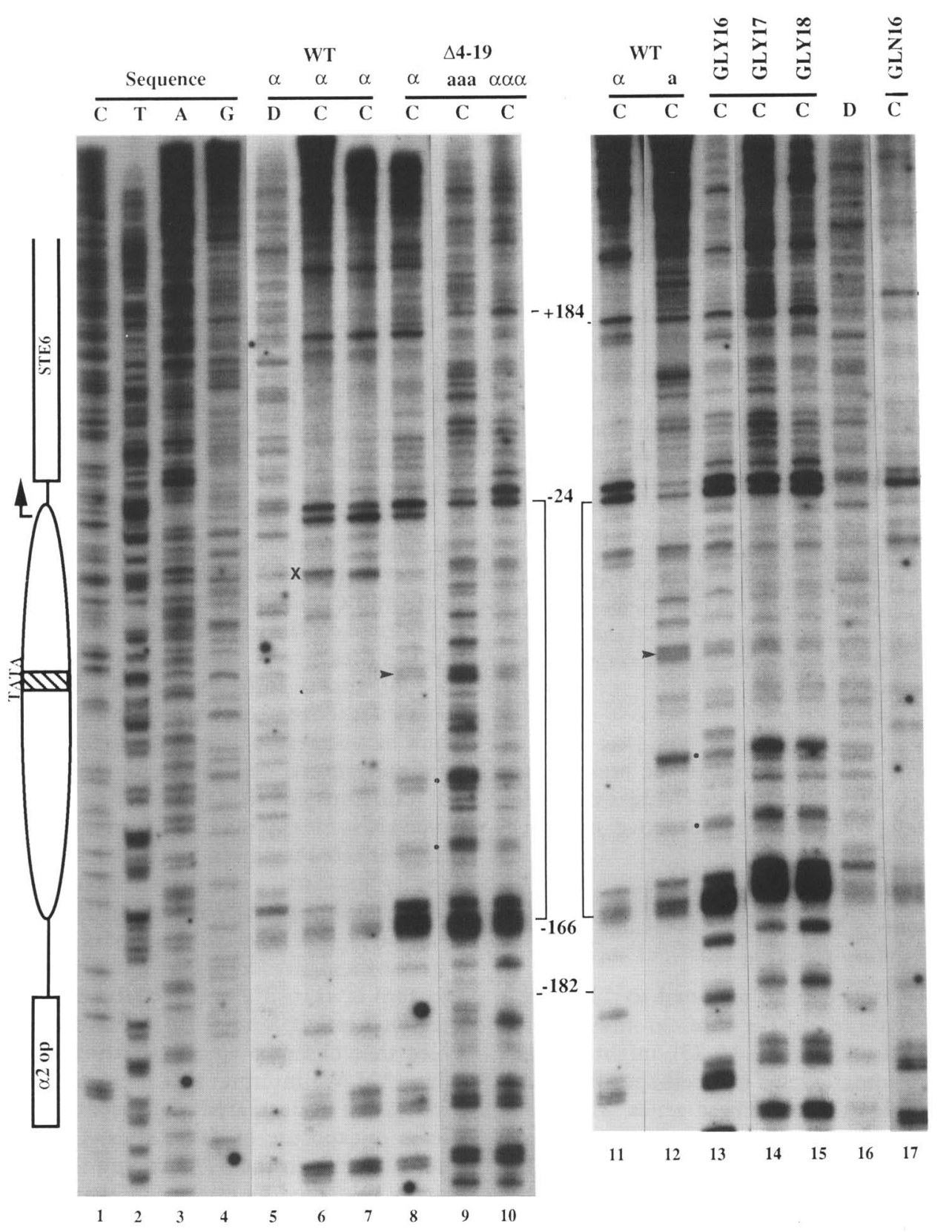

Figure 5. Chromatin structure of STE6 in the presence of H4 amino-terminal deletions and point mutations. $(A)$ The chromatin structure of sequences upstream of the a-cell-specific gene STE6 was analyzed by primer extension mapping of MNase cut sites in chromatin (C) or DNA (D) isolated from unrelated $\alpha$ cells (SC3) (lanes 6,11), $\alpha$ cells containing a single copy of wild-type H4 (PKY999 (isogenic to H4 mutations); lane 7], unrelated a cells (E290; lane 12), or isogenic $\alpha$ cells containing H4 mutations (lanes 8-10,13-17) as indicated. The del (4-19) was analyzed in strains PKY918 ( $\alpha)$, LJY438I (aaa), and JTY222H $(\alpha \alpha \alpha)$. The H4 point mutations were in strains PKY505 (Gly-16), LJY921 (Gly-17), LJY933 (Gly-18), and LJY612 (Gln-16). The position of the mRNA start site is indicated by the bent arrow in the diagram at left, and the locations of the $\alpha 2$ operator, putative TATA sequences, and the 5 ' portion of the STE6-coding region are shown (Wilson and Herskowitz 1986). The ellipse indicates the inferred position of a nucleosome in the promoter region. $(x)$ A band corresponding to an artifactual primer extension stop, not a MNase cut site; it is present in undigested samples (data not shown; Shimizu et al. 1991). The arrowhead marks cut sites that map to the TATA sequence. The dots correspond to cuts near pheromone response elements (Kronstad et al. 1987). Chromatin was digested with $5 \mathrm{U} / \mathrm{ml}$ (lanes 6-8,13-16), or 20 U/ml (lanes 9-12,17) of MNase. DNA was digested with $0.5 \mathrm{U} / \mathrm{ml}$ of MNase (lanes 5,15). Cleavage of chromatin from a given strain always produced the same pattern of bands, regardless of the concentration of nuclease used, except for a progressive loss of higher-molecularweight bands with increasing concentrations of nuclease. Concentrations were chosen for display to optimize comparison between various samples. 
ner in the presence of del (4-19), with exposure of sites normally protected by a nucleosome in $\alpha$ cells, but with maintenance of hypersensitive sites at the ends of this region (data not shown).

\section{Point mutations in the $\mathrm{H} 4$ amino-terminal region affect STE6 chromatin structure}

Point mutation of amino acids $15-19$ in H4 elicits a phenotype similar to that of del (4-19), including an alteration of growth rate and derepression of the $H M L$ silent mating-type locus (Johnson et al. 1990). We investigated whether such mutations would also lead to alterations in the chromatin structure of the STE6 promoter region. Examination of STE6 structure in the presence of individual point mutations converting Lys-16, Arg-17, or His-18 (Fig. 1C) to glycyl residues revealed alterations in nucleosome stability extremely similar to those described above for del (4-19) (Fig. 5, cf. lanes 13, 14, and 15 with lane 10). Sites normally protected by nucleosomes in the promoter region and the first $184 \mathrm{bp}$ of coding sequence are exposed in these strains, whereas hypersensitive sites at either end of these regions were maintained. Surprisingly, although substitution of glycine for Lys-16 (Gly-16) resulted in a changed STE6 chromatin structure (lane 12), substitution of glutamine at this position (Gln-16), either on a plasmid (data not shown) or as an integrated allele, did not (lane 17; note similarity to lanes 6 and 7). The ability of the individual glycyl substitutions at residues 16,17 , or 18 to alter the structure of the STE6 promoter region highlights the importance of this region of $\mathrm{H} 4$ to the stable positioning of nucleosomes normally observed adjacent to the $\alpha 2$ operator in $\alpha$ cells.

\section{Occupancy of the $\alpha 2$ operator is not changed in the presence of del (4-19)}

Changes in nucleosome position and stability might affect the association of trans-acting factors with chromatin. To rule out the possibility that the binding of $\alpha 2$ to its operator sequence might be altered in the presence of the $\mathrm{H} 4$ amino-terminal mutations, we performed in vivo footprints of the operator region by treating intact cells with DMS.

In vitro analysis of $\alpha 2$ binding to its operator by DMS footprinting indicates that symmetrical $G$ residues at each end of the operator are protected by $\alpha 2$ (Sauer et al. 1988). These same residues are protected in vivo in wildtype $\alpha$ cells (M. Shimizu, unpubl.; Fig. 6) but not in a cells, in the absence of $\alpha 2$. In addition, other, more centrally located $G$ residues are at least partially protected in both cell types (Fig. 6), consistent with the binding of MCMl in this region. This pattern of protection is not changed in the presence of the del (4-19) H4 deletion, indicating that occupancy of the operator in these cells is equivalent to that in wild-type $\alpha$ cells (Fig. 6). A more detailed analysis of the binding of $\alpha 2$ and MCM1 to chromatin in vivo is the subject of a separate study (M. Shimizu, S.Y. Roth, M. Murphy, and R.T. Simpson, unpubl.).

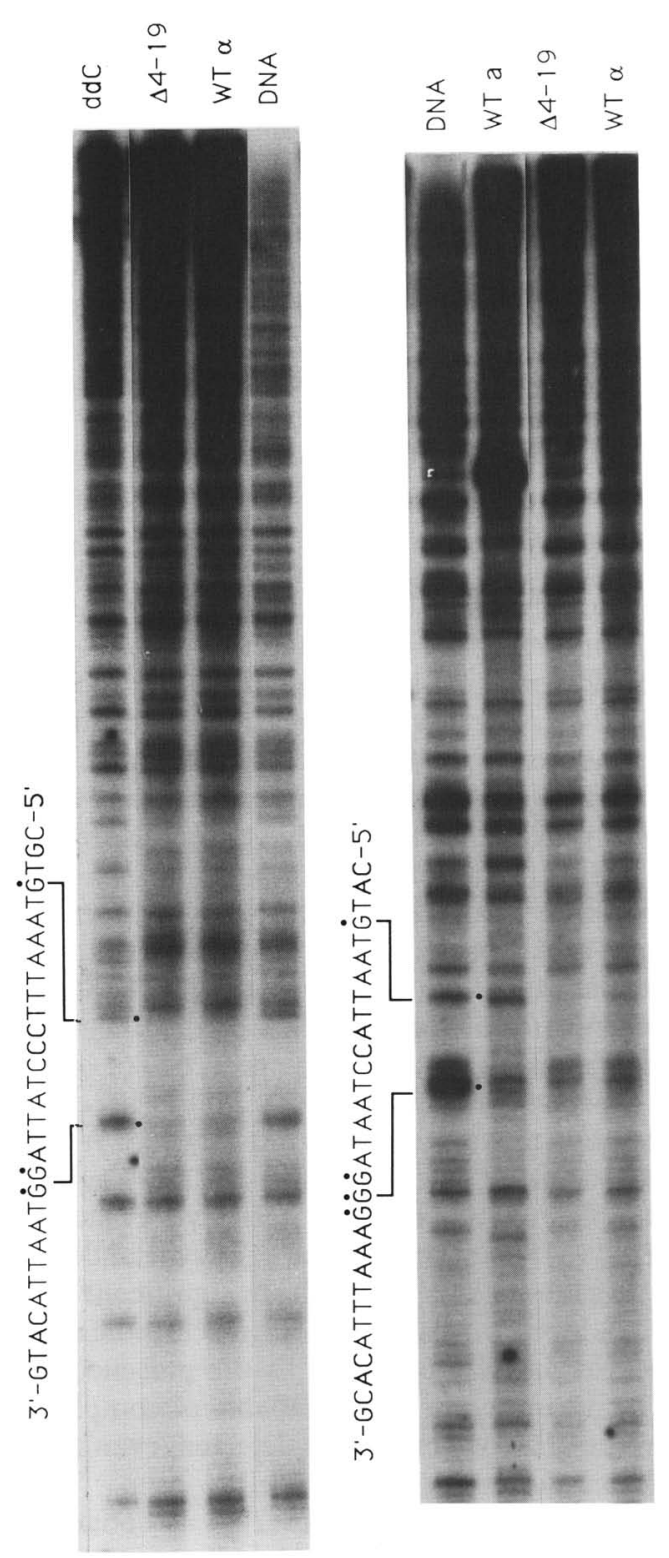

Figure 6. In vivo DMS footprinting of the $\alpha 2$ operator. DNA purified from intact cells treated with DMS was subjected to multicycle primer extension. Sites of methylation in both strands of the $\alpha 2$ operator were mapped in wild-type $\alpha$ cells, $\alpha$ cells containing del $(4-19)$, or wild-type a cells and compared to a ddC sequencing reaction (ddC) or DMS-treated naked DNA (DNA). Protected sites are indicated by dots next to the corresponding band in naked DNA and above the corresponding G residue in the sequences shown at left.

\section{Incomplete repression by $\alpha 2$ in the presence of $\mathrm{H} 4$ amino-terminal mutations}

If nucleosomes positioned adjacent to the $\alpha 2$ operator in the promoter regions of a-cell-specific genes contribute to the repression of these genes in $\alpha$ cells, increased expression should accompany alterations of nucleosome stability or position. To test this hypothesis, we replaced the a-cell-specific gene $M F \mathbf{a} 2$ (mating factor a2) in iso- 
genic strains harboring the $\mathrm{H} 4$ amino-terminal mutations with a $M F \mathbf{a} 2-\beta$-galactosidase fusion gene.

Expression of the $\beta$-galactosidase reporter gene was monitored by development of blue color in colonies plated on media containing X-gal and by measurement of $\beta$-galactosidase activity (Fig. 7). Although no blue color developed in wild-type $\alpha$ cells (Fig. 7A), a faint blue color was observed in the del (4-14) strain, and more intense expression was observed in colonies bearing del (4-19), del (4-23), Gly-16, and Gly-18 (no transformants of the Gly-17 strain bearing the integrated reporter gene were recovered; see Materials and methods). Strong expression of the $\beta$-galactosidase fusion protein was observed in wild-type a cells, as expected.

$\beta$-Galactosidase activity measured in liquid assay indicated no expression above background in the wild-type $\alpha$ strain and minimal expression in the del $(4-14)$ strain. A level of expression intermediate to that in wild-type $\alpha$ and a cells was observed in the presence of the other $\mathrm{H} 4$ mutations, reaching $4-15 \%$ of the maximal expression observed in a cells (Fig. 7B). Increased steady-state levels of $M F \mathbf{a} 2-\beta$-galactosidase mRNA were also observed in these strains (data not shown).

Importantly, partial derepression was observed in the presence of del (4-19) in two isogenic strains differing only at the MAT locus (PKY918 and PKY818) and in the nonisogenic $\alpha \alpha \alpha$ strain (JTY222H) (Fig. 7), indicating that derepression occurs in the presence of one, two, or three expressed copies of MAT $\alpha$ and is independent of the presence of a-mating-type information. We have also observed a partial derepression of a STE6- $\beta$-galactosidase reporter plasmid and of BARl activity (Sprague and Herskowitz 1981) (data not shown). The partial derepression of these genes seems particularly significant in view of the DMS footprint data (Fig. 6), which indicate that the $\alpha 2$ operator is fully occupied in the presence of del 14 19). The $\alpha 2$ repressor is not capable of complete repression in the presence of this $\mathrm{H} 4$ deletion, even though it is bound to its operator in these cells.

The partial derepression observed is consistent with the partial change in STE6 chromatin structure that occurs in the presence of the $\mathrm{H} 4$ mutations. Indeed, the lack of a more extensive derepression (relative to a cells) may reflect the residual organization of chromatin in the H4 mutant strains. Significantly, in every strain examined so far, mutations that alter nucleosome position/ stability adjacent to the $\alpha 2$ operator also result in incomplete repression by $\alpha 2$. Conversely, mutations such as the $\mathrm{H} 2 \mathrm{~B}$ amino-terminal deletion and the H4 Gln-16 mutation that do not affect STE6 chromatin structure also do not affect repression by $\alpha 2$ (data not shown). Our finding that the $\mathrm{H} 4$ amino-terminal region is required both for stable positioning of nucleosomes adjacent to the $\alpha 2$ operator and for efficient repression by $\alpha 2$ indicates a direct role for chromatin structure in the regulation of a-cell-specific gene expression.

\section{Discussion}

Nucleosomes are precisely positioned adjacent to the $\alpha 2$ operator in the presence of $\alpha 2$ in several different sequence contexts (Roth et al. 1990; Simpson 1990; Shimizu et al. 1991). Here, we show that the aminoterminal region of $\mathrm{H} 4$ is required for stable translational and rotational positioning of these nucleosomes as well as for efficient repression by $\alpha 2$, indicating that chromatin structure directly contributes to the regulation of cell-type-specific gene expression in yeast.

\section{Mechanism of nucleosome positioning by $\alpha 2$}

Positioning of nucleosomes adjacent to the $\alpha 2$ operator could occur indirectly upon binding of $\alpha 2 / \mathrm{MCM} 1$ through formation of a boundary to nucleosome placement. However, statistical positioning around the operator (Kornberg 1981; Kornberg and Stryer 1988) cannot explain the ability of the operator to induce a shift in nucleosome position (Simpson 1990) or the precision of positioning observed adjacent to the operator /Shimizu et al. 1991; this paper). Also, because MCM1 binds the operator in both a and $\alpha$ cells (Keleher et al. 1988; Passmore et al. 1988), statistical positioning might be expected to occur in both cell types. Moreover, the positions of nucleosomes IV and V are destabilized in the presence of the $\mathrm{H} 4$ del (4-19) mutation, even though in vivo footprinting of the $\alpha 2$ operator indicates that it is occupied in these cells. Our data support a more direct mechanism for positioning of nucleosomes adjacent to the operator, involving the $\alpha 2 / \mathrm{MCM} 1$ complex and the $\mathrm{H} 4$ aminoterminal region.

It is surprising that nucleosome position is not randomized upon destabilization of nucleosomes IV and V in TALS, given the lack of organization observed in a cells (Roth et al. 1990). Although it is possible that $\alpha 2$

Figure 7. Expression of a reporter construct regulated by $\alpha 2$ in the presence of $\mathrm{H} 4$ mutations. $(A)$ Cells containing the $M F \mathrm{a} 2-\beta$ galactosidase reporter construct grown on X-gal media. Wild-type $\alpha$ cells shown are PKY999; wild-type a cells are PKY899. Mutant H4 strains are as listed in $B$. The del (4-19) [PKY918 and JTY222H ( $\alpha \alpha \alpha)]$ and del (4-23) (PKY913) strains exhibit a characteristic slow-growth phenotype (Kayne et al. 1988). (B) $\beta$-Galactosidase expression in permeabilized cells was determined as described by Rose et al. (1990) and is expressed in Miller units. Values normalized by subtraction of activity present in cells without the reporter gene are shown (normalized), as are average values of activity in each strain (LacZ; \pm S.D.). The number of determinations [n] is indicated for each. The \% Max values represent activities divided by that present in isogenic, wild-type a cells. For all strains except PKY505 and LJY933, the isogenic a strain is PKY899; for these two strains, it is PKY501. PKY899 and PKY501 are isogenic except for the vector carrying the wild-type $\mathrm{H} 4$ allele. No \% Max values are given for the $\alpha \alpha \alpha$ and aaa strains because they are not isogenic to the other strains. Strain names refer to the strains into which the reporter gene was introduced. The resultant transformants have the same names followed by "MFZ" to designate the integration. 


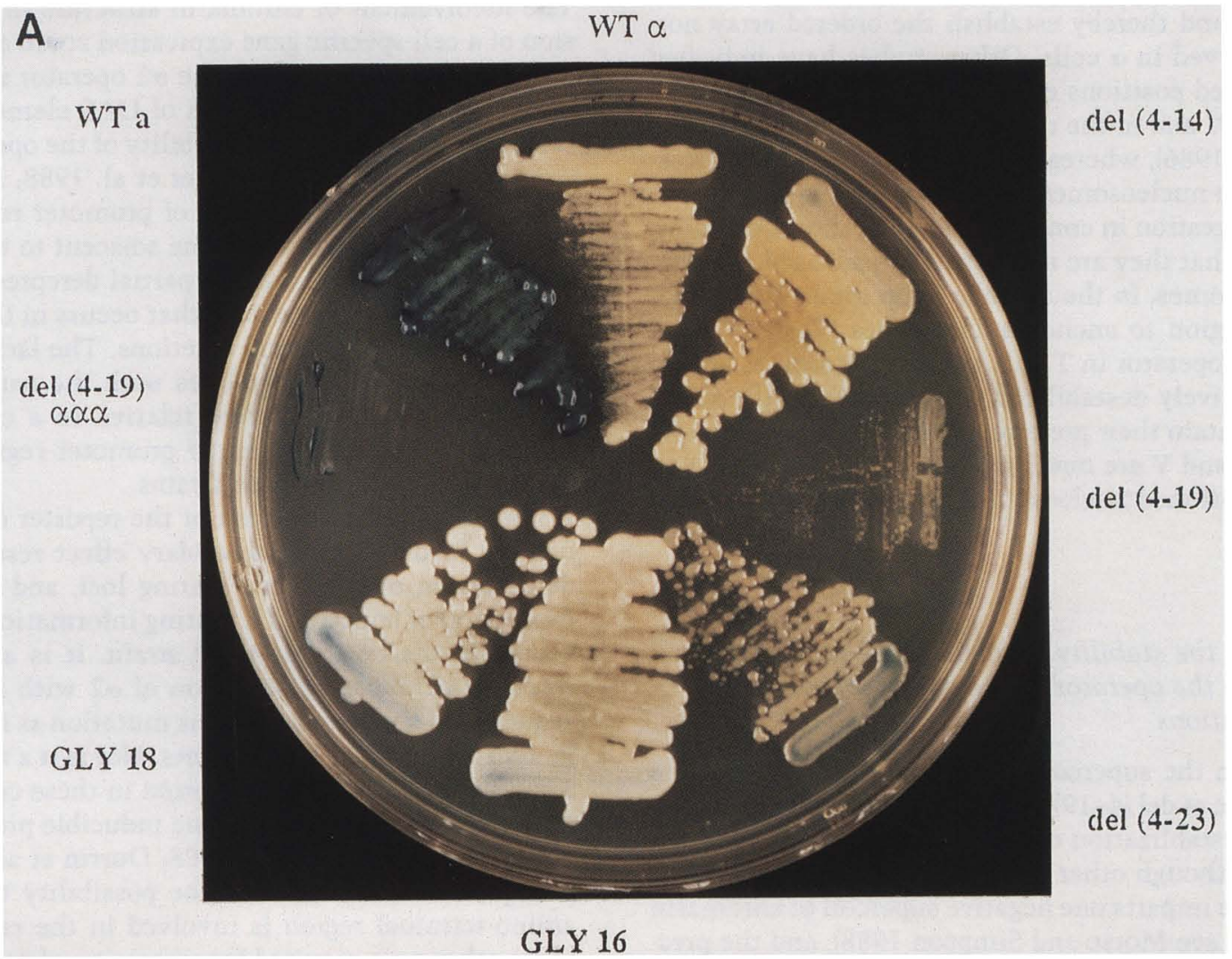

B

\begin{tabular}{|c|c|c|c|c|c|c|c|c|c|}
\hline Strain & H4 Allele & Reporter & HML & MAT & HMR & $\operatorname{Lac} Z$ & [n] & Normalized & $\% \operatorname{Max}$ \\
\hline PKY999 & wt & - & $\alpha$ & $\alpha$ & a & $1.5+/-0.2$ & [3] & 0 & 0 \\
\hline PKY999 & wt & + & $\alpha$ & $\alpha$ & a & $1.5+/-0.7$ & [14] & 0 & 0 \\
\hline PKY917 & $d(4-14)$ & + & $\alpha$ & $\alpha$ & $a$ & $1.6+/-0.5$ & [10] & 0.1 & 0.3 \\
\hline PKY918 & $d(4-19)$ & + & $\alpha$ & $\alpha$ & a & $4.4+/-1.4$ & [9] & 2.9 & 7.4 \\
\hline PKY818 & $d(4-19)$ & + & $\alpha$ & a & a & $7.3+/-2.7$ & [6] & 5.8 & 14.8 \\
\hline PKY913 & $d(4-23)$ & + & $\alpha$ & $\alpha$ & a & $4.7+/-1.6$ & [12] & 3.2 & 8.2 \\
\hline PKY505 & GLY 16 & + & $\alpha$ & a & a & $3.0+/-1.5$ & [6] & 1.5 & 4.4 \\
\hline LJY933 & GLY18 & + & $\alpha$ & $a$ & a & $3.7+/-0.6$ & [8] & 2.2 & 6.4 \\
\hline PKY899 & wt & + & $\alpha$ & a & a & $40.7+/-11$ & [11] & 39.2 & 100 \\
\hline PKY501 & wt & + & $\alpha$ & a & a & $35.8+/-10$ & {$[7]$} & 34.3 & 100 \\
\hline JTY222H & $d(4-19)$ & + & $\alpha$ & $\alpha$ & $\alpha$ & $4.0+/-1.3$ & {$[4]$} & 2.5 & - \\
\hline LJY4381 & $d(4-19)$ & + & a & a & a & $25+/-4.8$ & [6] & 23.5 & - \\
\hline
\end{tabular}

Figure 7. (See facing page for legend.) 
might act at a distance to maintain the positions of distal nucleosomes, it seems more plausible that nucleosomes IV and V may form transiently in the presence of the $\mathrm{H} 4$ mutations and thereby establish the ordered array normally observed in $\alpha$ cells. Other studies have indicated that preferred positions exist for nucleosomes in the region of TRP1 and in the regions of nucleosomes I, II, and III (Thoma 1986), whereas TRP1/ARS1 sequences incorporated into nucleosomes IV and V are hypersensitive to nuclease digestion in constructs lacking the $\alpha 2$ operator, indicating that they are not normally packaged into stable nucleosomes. In the absence of an intact $\mathrm{H} 4$ aminoterminal region to anchor nucleosomes IV and $\mathrm{V}$ adjacent to the operator in TALS, these nucleosomes appear to be selectively destabilized while more distal nucleosomes maintain their preferred positions. Because nucleosomes IV and V are never positioned in the absence of $\alpha 2$, the positioned nucleosomal array does not form in a cells.

\section{Changes in the stability of nucleosome position adjacent to the operator in the presence of $\mathrm{H} 4$ mutations}

The shift in the supercoil density of TALS observed in the presence of del $(4-19)$ and $\operatorname{del}(4-23)$ is also consistent with the destablization of a nucleosome adjacent to the operator, although other explanations are possible. Each nucleosome imparts one negative supercoil to chromatin (for review, see Morse and Simpson 1988), and the presence of an additional negative supercoil in strains expressing wild-type $\mathrm{H} 4$ or del $(4-14)$ could indicate the presence of one more stable nucleosome on the plasmid in these strains. Increased acetylation of histones, which neutralizes positively charged lysyl residues, has been observed to decrease the negative linking number change per nucleosome (Norton et al. 1989). Deletion of aminoterminal lysines in $\mathrm{H} 4$ might mimic this effect, leading to an overall decrease in the negative superhelicity of chromatin as is observed for TALS in the presence of del (4-19) or del (4-23). However, our observation that such shifts in supercoil density do not occur for plasmids that do not contain the $\alpha 2$ operator indicates that a decreased negative superhelicity is not a general feature of chromatin in these cells. Changes in supercoil density might also be associated with changes in transcriptional activity. However, no induction of TRP1 RNA accumulation was observed in the presence of del (4-19) or del (4-23) (data not shown), so the change in supercoil density is not easily explained by an increase in TRP1 transcription, unless such an increase is accompanied by an increased turnover of TRP1 RNA. It is also unlikely, therefore, that the changes in the positions of nucleosomes IV and $\mathrm{V}$ observed in the presence of these mutations stem from increased transcription of TRP1. The lack of an increase in TRP1 expression is consistent with a continued repression of this gene by nucleosomes (VI, VII) positioned upstream of the TRP1 RNA start site (at 105 map units, Fig. 1A).
Promoter accessibility and regulation of a-cell-specific gene expression

The involvement of chromatin structure in the repression of a-cell-specific gene expression could explain how repression can occur when the $\alpha 2$ operator is placed either upstream or downstream of UAS elements in heterologous promoters and the ability of the operator to act over varying distances (Keleher et al. 1988; Herskowitz 1989|. Increased accessibility of promoter regions upon destabilization of a nucleosome adjacent to the $\alpha 2$ operator most easily explains the partial derepression of the $\beta$-galactosidase reporter gene that occurs in the presence of the $\mathrm{H} 4$ amino-terminal deletions. The lack of full induction of this gene correlates with the partial disruption of chromatin structure relative to a cells, which indicates that accessibility of promoter regions is still partially obscured in these strains.

Importantly, derepression of the reporter construct is not the result of some secondary effect resulting from derepression of the silent mating loci, and subsequent expression of both a and $\alpha$ mating information, as it also occurs in the $\alpha \alpha \alpha$ del $(4-19)$ strain. It is also not the result of an altered association of $\alpha 2$ with its operator sequence in the presence of this mutation as indicated by in vivo footprinting experiments. Nor is it a reflection of a general increase in transcription in these cells because other repressed genes and some inducible promoters are not activated (Kayne et al. 1988; Durrin et al. 1991). Although we cannot rule out the possibility that the $\mathrm{H} 4$ amino-terminal region is involved in the regulation of some other gene required for repression of a-cell-specific genes, the alterations in chromatin structure adjacent to the $\alpha 2$ operator in the presence of the $\mathrm{H} 4$ mutations suggest a direct involvement of the $\mathrm{H} 4$ amino-terminal tail in the maintenance of this structure and, thereby, efficient repression by $\alpha 2$.

\section{Other factors involved in regulation of a-cell-specific gene expression and chromatin structure}

The incomplete disruption of chromatin structure in the presence of the $\mathrm{H} 4$ mutations indicates that other factors, or other regions of $\mathrm{H} 4$, may be involved in the maintenance of this structure. At least two other proteins are involved in the control of a-cell-type-specific gene expression, SSN6 and TUP1 (Carlson et al. 1984; Trumbly 1986; Schultz and Carlson 1987; Schultz et al. 1990; Williams and Trumbly 1990). Interestingly, glucose-repressible genes that are also regulated by SSN6 and TUP1 undergo changes in chromatin structure upon activation (Lohr 1984; Perez-Ortin et al. 1987). Other histones could be important in the maintenance of nucleosome position/stability adjacent to the $\alpha 2$ operator as well, although an amino-terminal deletion in H2B had minimal effects on the structure of the TALS minichromosome or STE6, and strains bearing amino-terminal deletions in $\mathrm{H} 2 \mathrm{~A}$ have no obvious phenotype or effect on mating (for review, see Grunstein 1990a). However, an amino-terminal deletion in $\mathrm{H} 3$ causes a constitutive ex- 
pression of GAL1 (Durrin et al. 1991), and mutations in $\mathrm{H} 2 \mathrm{~A}$ and $\mathrm{H} 2 \mathrm{~B}$ can restore transcriptional initiation downstream of solo $\delta$ and TY insertions, rescuing expression of downstream genes (Clark-Adams et al. 1988). These histones, then, are an important part of some regulatory chromatin structures.

\section{Modulation of transcription by $\mathrm{H} 4$}

The involvement of the $\mathrm{H} 4$ amino terminus in the activation of some genes (Durrin et al. 1991) and repression of others (Kayne et al. 1988; Johnson et al. 1990; Aparico et al. 1991; this paper) indicates that this histone is important in the organization of chromatin structures that either facilitate or inhibit transcription. Direct or indirect interactions between $\mathrm{H} 4$ amino-terminal domains and trans-acting factors such as GAL4 (Durrin et al. 1991), SIR3 (Johnson et al. 1990), and $\alpha 2$ may determine the type of structure formed. These interactions could easily be influenced by post-translational modification of the $\mathrm{H} 4$ amino-terminal tail, providing a mechanism whereby changes in promoter accessibility and transcriptional activity could be readily accomplished. The extreme conservation of the $\mathrm{H} 4$ amino-terminal region suggests that it may be involved in the regulation of gene expression in other organisms as well. A role in modulation of transcriptional activity might explain why this region of the $\mathrm{H} 4$ molecule is so highly conserved and yet is not essential for yeast cell viability.

\section{Materials and methods}

Yeast strains

S. cerevisiae strains were propagated according to standard procedures (Rose et al. 1990) in either rich media (YEPD) or selec- tive media (SDM containing appropriate amino acids, adenine, and uracil if needed) as necessary. Strains used are presented in Table 1.

Construction of plasmids and yeast strains containing the MFa2- $\beta$-galactosidase fusion gene

Construction of the yeast plasmid TALS has been described previously (Roth et al. 1990). One-step gene replacement of the $M F a 2$ gene in the various strains listed in Figure 7 was performed using standard techniques (Rose et al. 1990). Because no selection for the integration was available, a linear HindIII fragment from the plasmid pSM38 (generously provided by Susan Michaelis, Johns Hopkins University, Baltimore, MD) containing the $M F \mathbf{a} 2-\beta$-galactosidase fusion gene was cotransformed with a TRP1/ARS1 plasmid at a ratio of $\sim 10: 1$ (linear/plasmid) by mass. $\mathrm{TRP}^{+}$transformants were replica plated to media containing X-gal. Cotransformants $\left(\mathrm{TRP}^{+} ; \beta\right.$-galactosidase $+\mid$ arose at frequencies ranging between $0.5 \%$ and $3 \%$ in the $\mathrm{H} 4$ mutant strains with the exception of the Gly-17 mutant. For reasons not understood, this mutant reproducibly gave insufficient numbers of $\mathrm{TRP}^{+}$transformants to facilitate screening for cotransformants. Blue colonies in the other strains were picked, and integration of the fusion gene at the MFa2 locus was confirmed by Southern blot analysis using standard techniques (Sambrook et al. 1989). In the case of the wild-type $\alpha$ strain (PKY999), the reporter gene was repressed, as expected, so no blue color selection was available. In this case, colonies were screened directly by Southern analysis for the presence of the MFa2- $\beta$-galactosidase integration.

A $M F a 2-\beta$-galactosidase reporter plasmid was constructed by ligating a 4.5-kb HindIII fragment from the plasmid pSM38 into the HindIII site of YCp50 (Rose et al. 1987). Bacterial clones were identified by restriction analysis; DNA was prepared and introduced into yeast using standard techniques (Rose et al. 1990). This plasmid was used to transform ura3 $3^{-}$strains including JTY222H $(\alpha \alpha \alpha)$, LJY438I (aaa), LJY656, and LJY612 (Gln-16); $\mathrm{URA}^{+}$transformants were selected and the presence of the plasmid was confirmed by Southern analysis.

Table 1. Strain list

\begin{tabular}{|c|c|c|}
\hline Strain & Genotype & Reference \\
\hline PKY999 & 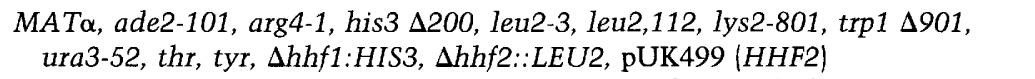 & Kayne et al. (1988) \\
\hline PKY917 & isogenic to PKY999 except pPK917 [hhf2 del(4-14)] instead of pUK499 & Kayne et al. (1988) \\
\hline PKY918 & isogenic to PKY999 except pPK618 [hhf2 del(4-19)] instead of pUK499 & Kayne et al. (1988) \\
\hline PKY818 & isogenic to PKY918 except MATa & Kayne et al. (1988) \\
\hline PKY913 & isogenic to PKY999 except pPK613 [hhf2 del(4-23)] instead of pUK499 & Kayne et al. (1988) \\
\hline PKY899 & isogenic to PKY999 except MATa & Kayne et al. (1988) \\
\hline PKY505 & isogenic to PKY899 except pPK305 (hhf2 Gly-16 URA ${ }^{+}$) instead of pUK499 & Johnson et al. (1990) \\
\hline LJY921 & isogenic to PKY505 except pLJ921 (hhf2 Gly-17 URA ${ }^{+}$) instead pPK305 & Johnson et al. (1990) \\
\hline LJY933 & isogenic to PKY505 except pLJ933 (hhf2 Gly-18 URA ${ }^{+}$) instead of pPK305 & Johnson et al. $(1990)$ \\
\hline PKY501 & isogenic to PKY505 except pPK301(HHF2) instead of pPK305 & Kayne et al. (1988) \\
\hline LJY656I & MAT $\alpha$, hhf1::HIS3, hht2::TRP1, trp1, lys2, ade2, his3, leu2, ura3 & L. Johnson \\
\hline LJY612I & isogenic to LJY656I except $h$ hf2 Gln-16 & L. Johnson \\
\hline JTY222H & $\begin{array}{l}H M L \alpha, M A T \alpha, H M R \alpha, \text { leu2,3,112, ura3-52, trp1, ade2, lys2, hhf1::HIS3, hhf2, } \\
\quad \text { del(4-19), hht2::TRP1 }\end{array}$ & $\begin{array}{l}\text { M. Grunstein and } \\
\text { J. Thompson }\end{array}$ \\
\hline LJY438I & $\begin{array}{l}\text { HMLa, MATa, HMRa, ade2-101, his3-200, leu2-3,112, lys2-801, trp1-901, } \\
\text { ura3-52, hhf1::HIS3, hhf2::del(4-19), hht2::TRP1 }\end{array}$ & Johnson et al. (1990) \\
\hline SC3 & $M A T \alpha$, ura3-53, trp1, his3, gal2, gal10, cir ${ }^{\circ}$ & Roth et al. (1990) \\
\hline E290 & MATa, his4-290, trp1 & Roth et al. (1990) \\
\hline TSY155 & MATo, ura3-52, htb1-1, htb2-1, ade2-101, trp1, met13, pTS7 [htb2 del(3-32)] & Wallis et al. (1983) \\
\hline YP47 & MATa, ura3-52, lys2-801, ade2-101, trp1 & Wallis et al. (1983) \\
\hline
\end{tabular}




\section{Isolation and analysis of chromatin by indirect end-labeling}

Chromatin was partially purified and digested with MNase as described previously (Thoma et al. 1986; Roth et al. 1990). Chromatin samples were digested with $2 \mathrm{U} / \mathrm{ml}$ (Fig. $2 \mathrm{~A}$ ), $5 \mathrm{U} / \mathrm{ml}$, or $10 \mathrm{U} / \mathrm{ml}$ (Fig. 2B) of MNase, and DNA was digested with 0.5 $\mathrm{U} / \mathrm{ml}$ (Fig. $2 \mathrm{~A}$ ) or $5 \mathrm{U} / \mathrm{ml}$ (Fig. $2 \mathrm{~B}$ ) of $\mathrm{MNase}$ at $37^{\circ} \mathrm{C}$ for $5 \mathrm{~min}$. DNA was purified, subjected to restriction endonuclease digestion, fractionated on agarose gels, transferred to nitrocellulose, and probed with specific fragments of TALS labeled with ${ }^{32} \mathrm{P}$ as described previously (Roth et al. 1990). The blots in Figure 2 were probed with an EcoRV-HindIII fragment ( $230 \mathrm{bp}$ ) of TALS.

\section{Analysis of TALS supercoil density}

DNA was isolated and topoisomers were resolved as described previously (Roth et al. 1990) and fractionated on $1.5 \%$ agarose gels containing $40 \mu \mathrm{g} / \mathrm{ml}$ of chloroquine diphosphate (Sigma Chemical Co.) in both the gel and electrophoresis buffer. Under these conditions, more negatively supercoiled molecules migrate more slowly than less negatively supercoiled molecules. After electrophoresis, samples were transferred to nitrocellulose and analyzed as described previously (Roth et al. 1990).

Isolation of nuclei and primer extension analysis of nuclease cleavage sites

Nuclei were isolated as described by Szent-Gyorgyi and Isenberg (1983), except that dithiothreitol was used instead of 2-mercaptoethanol, and Zymolyase 100T (ICN) was used instead of lyticase (Roth and Simpson 1991). Nuclei were digested in digestion buffer (10 mM HEPES ( $\mathrm{pH} 7.5$ ), $0.5 \mathrm{mM} \mathrm{MgCl}_{2}, 0.05$ $\mathrm{mM} \mathrm{CaCl}$ ] for $10 \mathrm{~min}$ at $37^{\circ} \mathrm{C}$ using concentrations of $\mathrm{MNase}$ or DNase I listed in the legends to Figures 3 and 4. DNA was purified (Szent-Gyorgyi and Isenberg 1983), and fragments were analyzed by either single cycle (Fig. 3) or multicycle (Fig. 4) primer extension using Taq polymerase, as described previously (Axelrod and Majors 1989; Shimizu et al. 1991), with the addition of a 5 -min preincubation of samples at $95^{\circ} \mathrm{C}$ followed by quick chilling of samples in ice water before the addition of polymerase. Sequencing gel electrophoresis was performed by standard procedures (Sambrook et al. 1989). Single-cycle primer extension conditions were $95^{\circ} \mathrm{C}, 5 \mathrm{~min} ; 48^{\circ} \mathrm{C}, 20 \mathrm{~min}$; and $70^{\circ} \mathrm{C}$, $5 \mathrm{~min}$. Multicycle conditions were $94^{\circ} \mathrm{C}, 1 \mathrm{~min} ; 55^{\circ} \mathrm{C}, 2 \mathrm{~min}$; and $73^{\circ} \mathrm{C}, 3 \mathrm{~min}$. Typically, 15 cycles were performed. Primers used included MS-2 (1735-1702 map units in TALS, for the analysis of nucleosome IV), 5'-TTA GGC ACC CCA GGC TTT ACA CTT TAT GCT TCC GG-3'; MS-7 [-338 to -304 bp in STE6 upstream sequences /Wilson and Herskowitz 1986; McGrath and Varshavsky 1989)|, 5'-TGA TGG TCC TTG CAC TGA CAA ATA TGT TCC TTT CC-3'.

\section{In vivo footprinting of the $\alpha 2$ operator}

Intact, living cells were treated with DMS, and DNA was purified as described by Giniger et al. (1985) and Axelrod and Majors (1989), except that treatment with piperidine was omitted. Repeated heating to $94^{\circ} \mathrm{C}$ during the subsequent multicycle primer extension analysis (as above) was found to be sufficient for breakage at methylated G residues. Primers included MS-7 (above) and MS-8 (-55 to -89 in STE6 upstream sequences, 5'-TCT GTG TGA ACG TAA CAA CGG GAG ATA GTT CAGCC-3'].

\section{Measurement of $\beta$-galactosidase expression}

Transformants were patched onto X-gal containing selective media prepared as described previously (Rose et al. 1990) and incubated at $30^{\circ} \mathrm{C}$ or at room temperature for several days for development of blue color. $\beta$-Galactosidase activity was measured in permeabilized cells as described previously (Rose et al. $1990 \mid$.

\section{Acknowledgments}

We thank Anne Dranginis, Ann Dean, Jurrien Dean, Alan Wolffe, Randy Morse, Michael Murphy, David Roth, and Gary Felsenfeld for critical comments and reading of the manuscript, and Alan Hinnebusch and Susan Michaelis for the generous gifts of a pyruvate kinase probe and a MFa2- $\beta$-galactosidase clone, respectively. We also thank members of the National Institutes of Health Chromatin Club and the Washington Area Yeast Club for stimulating discussions.

The publication costs of this article were defrayed in part by payment of page charges. This article must therefore be hereby marked "advertisement" in accordance with 18 USC section 1734 solely to indicate this fact.

\section{References}

Aparico, O.M., B.L. Billington, and D.E. Gottschling. 1991. Modifiers of position effect are shared between telomeres and silent mating type loci in S. cerevisiae. Cell 66: 12791287.

Axelrod, J.D. and J. Majors. 1989. An improved method for photofootprinting yeast genes in vivo using TAQ polymerase. Nucleic Acids Res. 17: 171-183.

Carlson, M., B.C. Osmond, L. Neigeborn, and D. Botstein. 1984. A suppressor of snfl mutations causes constitutive highlevel invertase synthesis in yeast. Genetics 107: 19-32.

Clark-Adams, C.D., D. Norris, M.A. Osley, J.S. Fassler, and F. Winston. 1988. Changes in histone dosage alter transcription in yeast. Genes \& Dev. 2: 150-159.

Dolan, J.W. and S. Fields. 1991. Cell-type-specific transcription in yeast. Biochim. Biophys. Acta 1088: 155-169.

Dranginis, A.M. 1986. Regulation of cell type in yeast by the mating type locus. Trends Biochem. Sci. 11: 328-331.

-1990. Binding of yeast al and $\alpha 2$ as a heterodimer to the operator of a haploid specific gene. Nature 347: 682-685.

Durrin, L.K., R.K. Mann, P.S. Kayne, and M. Grunstein. 1991. Yeast histone $\mathrm{H} 4 \mathrm{~N}$-terminal sequence is required for promoter activation in vivo. Cell 65: 1023-1031.

Giniger, E., S.M. Varnum, and M. Ptashne. 1985. Specific DNA binding of GAL4, a positive regulatory protein of yeast. Cell 40: $767-774$.

Goutte, C. and A.D. Johnson. 1988. al protein alters DNA binding specificity of $\alpha 2$ repressor. Cell 52: 875-882.

Grunstein, M. 1990a. Histone function in transcription. Annu. Rev. Cell Biol. 6: 643-678.

- 1990b. Nucleosomes: Regulators of transcription. Trends Genet. 6: 395-400.

Hall, M.N. and A.D. Johnson. 1987. Homeodomain of yeast repressor $\alpha 2$ is a DNA binding domain but is not sufficient for repression. Science 237: 1007-1012.

Herskowitz, I. 1989. A regulatory hierarchy for cell specialization in yeast. Nature 342: 749-757.

Jensen, A.D., G.F. Sprague Jr., and I. Herskowitz. 1983. Regulation of yeast mating type interconversion: Feedback control of HO expression by mating type locus. Proc. Natl. Acad. Sci. 80: 3035-3039.

Johnson, A.D. and I. Herskowitz. 1985. A repressor (Mat $\alpha 2$ product) and its operator control expression of a set of cell type specific genes in yeast. Cell 42: 237-247. 
Johnson, L.M., P.S. Kayne, E.S. Kahn, and M. Grunstein. 1990. Genetic evidence for an interaction between SIR3 and histone $\mathrm{H} 4$ in the repression of silent mating loci in Sacchromyces cerevisiae. Proc. Natl. Acad. Sci. 87: 6286-6290.

Kayne, P.S., U. Kim, M. Han, J.R. Mullen, F. Yoshizaki, and M. Grunstein. 1988. Extremely conserved histone H4 N terminus is dispensable for growth but essential for repressing the silent mating loci in yeast. Cell 55: 27-39.

Keleher, C.A., C. Goutte, and A.D. Johnson. 1988. The yeast cell type specific repressor $\alpha 2$ acts cooperatively with a non cell type specific protein. Cell 53: 927-936.

Keleher, C.A., S. Passmore, and A.D. Johnson. 1989. Yeast repressor $\alpha 2$ binds to its operator cooperatively with yeast protein MCM1. Mol. Cell. Biol. 9: 5228-5230.

Kornberg, R.D. 1981. The location of nucleosomes in chromatin: Specific or statistical? Nature 292: 579-580.

Kornberg, R.D. and L. Stryer. 1988. Statistical distributions of nucleosomes: Nonrandom locations by a stochastic mechanism. Nucleic Acids Res. 16: 6677-6690.

Kronstad, J.W., J.A. Holly, and V.L. Mackay. 1987. A yeast operator overlaps an upstream activation site. Cell 50: 369377.

Laughton, A. and M.P. Scott. 1984. The sequence of a Drosophila segmentation gene: Protein structure homology with DNA binding proteins. Nature 310: $25-30$.

Lohr, D. 1984. Organization of the GAL1-GAL10 intergenic control region chromatin. Nucleic Acids Res. 12: 8457-8474.

McGrath, J.P. and A. Varshavsky. 1989. The yeast STE6 gene encodes a homologue of the mammalian multidrug resistance P-glycoprotein. Nature 340: 400-404.

Megee, P.C., B.A. Morgan, B.A. Mittman, and M.M. Smith. 1990. Genetic analysis of histone H4: Essential role of lysines subject to acetylation. Science 247: 841-845.

Miller, A.M., V.L. Mackay, and K.A. Nasmyth. 1985. Identification and comparison of two sequence elements that confer cell-type specific transcription in yeast. Nature 314: 598603.

Morse, R.H. and R.T. Simpson. 1988. DNA in the nucleosome. Cell 54: 285-287.

Nasmyth, K. and D. Shore. 1987. Transcriptional regulation in the yeast life cycle. Science 237: 1162-1170.

Norton, V.G., B.S. Imai, P. Yau, and E.M. Bradbury. 1989. Histone acetylation reduces nucleosome core particle linker number change. Cell 57: 449-457.

Park, E.-C. and J.W. Szostak. 1990. Point mutations in the yeast histone $\mathrm{H} 4$ gene prevent silencing of the silent mating type locus HML. Mol. Cell. Biol. 10: 4932-4934.

Passmore, S., G.T. Maine, R. Elbe, C. Christ, and B.-K. Tye. 1988. Sacchromyces cerevisiae protein involved in plasmid maintenance is necessary for mating of MAT $\alpha$ cells. J. Mol. Biol. 204: 593-606.

Passmore, S., E. Randolph, and B.-K. Tye. 1989. A protein involved in minichromosome maintenance in yeast binds a transcriptional enhancer conserved in eukaryotes. Genes \& Dev. 3: 921-935.

Pederson, D.S., M. Venkatesan, F. Thoma, and R.T. Simpson. 1986. Isolation of an episomal yeast gene and replication origin as chromatin. Proc. Natl. Acad. Sci. 83: 7206-7210.

Perez-Ortin, J.E., F. Estruch, E. Matallana, and L. Franco. 1987. Structure of the yeast SUC2 gene changes upon derepression. Comparison between chromosomal and plasmid-inserted genes. Nucleic Acids Res. 15: 6937-6956.

Rose, M.D., P. Novick, J.H. Thomas, D. Botstein, and G.R. Fink. 1987. A Sacchromyces cerevisiae genomic plasmid bank based on a centromere-containing shuttle vector. Gene 60: $237-243$.
Rose, M.D., F. Winston, and P. Hieter. 1990. Methods in yeast genetics: A laboratory course manual. Cold Spring Harbor Laboratory Press, Cold Spring Harbor, New York.

Roth, S.Y. and R.T. Simpson. 1991. Yeast minichromosomes. Methods Cell Biol. 35: 289-314.

Roth, S.Y., A. Dean, and R.T. Simpson. 1990. Yeast $\alpha 2$ repressor positions nucleosomes in TRP1/ARS1 chromatin. Mol. Cell. Biol. 10: 2247-2260.

Sambrook, J., E.F. Fritsch, and T. Maniatis. 1989. Molecular cloning: A laboratory manual, 2nd ed. Cold Spring Harbor Laboratory Press, Cold Spring Harbor, New York.

Sauer, R.T., D.L. Smith, and A.D. Johnson. 1988. Flexibility of the yeast $\alpha 2$ repressor enables it to occupy the ends of its operator, leaving the center free. Genes \& Dev. 2: 807-816.

Schultz, J. and M. Carlson. 1987. Molecular analysis of SSN6, a gene functionally related to SNFl kinase of Sacchromyces cerevisiae. Mol. Cell Biol. 7: 3637-3645.

Schultz, J., L. Marshall-Carlson, and M. Carlson. 1990. The N terminal TPR region is the functional domain of SSN6, a nuclear phosphoprotein of Sacchromyces cerevisiae. Mol. Cell. Biol. 10: 4744-4756.

Shimizu, M., S.Y. Roth, C. Szent-Gyorgyi, and R.T. Simpson. 1991. Nucleosomes are positioned with base pair precision adjacent to the $\alpha 2$ operator in Sacchromyces cerevisiae. EMBO I. 10: 3033-3041.

Simpson, R.T. 1990. Nucleosome positioning can affect the function of a cis-acting DNA element in vivo. Nature 343: 387-389.

- 1991. Nucleosome positioning: Occurrence, mechanisms, and functional consequences. Prog. Nucleic Acids Res. Mol. Biol. 40: 143-184.

Sprague, G.F., Jr. and I. Herskowitz. 1981. Control of yeast cell type by the mating type locus I: Identification and control of expression of the a-specific gene, BAR1. J. Mol. Biol. 153: 305-321.

Szent-Gyorgyi, C. and I. Isenberg. 1983. The organization of oligonucleosomes in yeast. Nucleic Acids Res. 11: 37173736.

Thoma, F. 1986. Protein-DNA interactions and nuclease sensitive regions determine nucleosome positions on yeast plasmid chromatin. J. Mol. Biol. 190: 177-190.

Trumbly, R.J. 1986. Isolation of Sacchromyces cerevisiae mutants constitutive for invertase synthesis. I. Bacteriol. 166: 1123-1127.

van Holde, K.E. 1989. The proteins of chromatin. I. Histones. In Chromatin (ed. A. Rich), pp. 69-180. Springer-Verlag, New York.

Wallis, J.W., M. Rykowski, and M. Grunstein. 1983. Yeast H2B containing large amino terminus deletions can function in vivo. Cell 35: 711-719.

Williams, F.E. and R.J. Trumbly. 1990. Characterization of TUP1, a mediator of glucose repression in Sacchromyces cerevisiae. Mol. Cell. Biol. 10: 6500-6511.

Wilson, K.L. and I. Herskowitz. 1986. Sequences upstream of the STE6 gene required for its expression and regulation by the mating type locus in Sacchromyces cerevisiae. Proc. Natl. Acad. Sci. 83: 2536-2540.

Wolffe, A.P. 1990. New approaches to chromatin function. New Biologist 2: 1-8. 


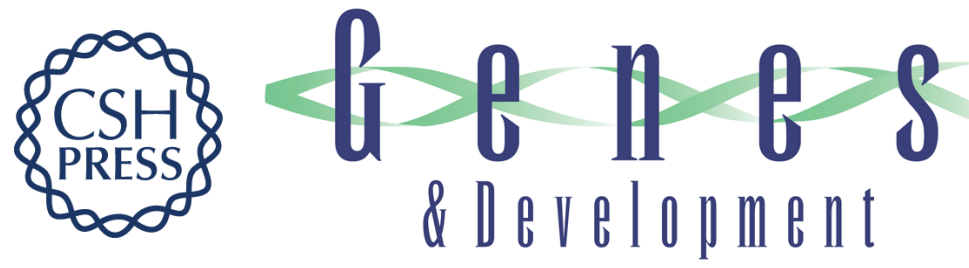

\section{Stable nucleosome positioning and complete repression by the yeast alpha 2 repressor are disrupted by amino-terminal mutations in histone H4.}

S Y Roth, M Shimizu, L Johnson, et al.

Genes Dev. 1992, 6:

Access the most recent version at doi:10.1101/gad.6.3.411

References This article cites 53 articles, 18 of which can be accessed free at: http://genesdev.cshlp.org/content/6/3/411.full.html\#ref-list-1

License

Email Alerting Service

Receive free email alerts when new articles cite this article - sign up in the box at the top right corner of the article or click here.

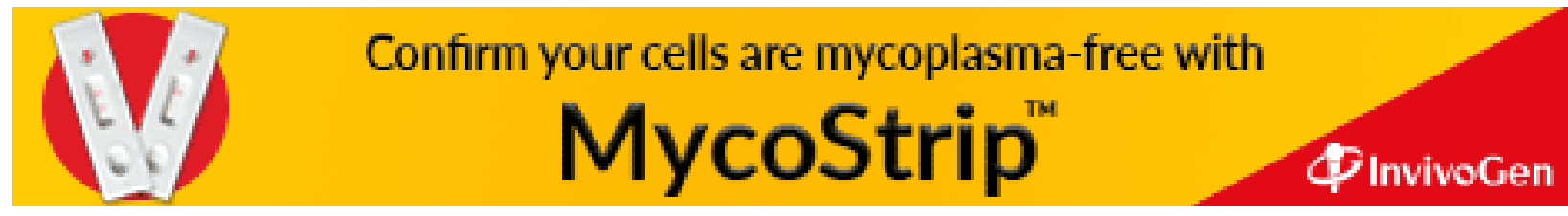

